\title{
The Potential Risk Associated with Foodborne Pathogens in Watersheds: Salmonellap spp. in Dairy Cattle
}

\author{
Rebecca Bordonaro, Patrick L. McDonough, Yung-Fu Chang, Hussni O. Mohammed \\ Section of Epidemiology, Department of Population Medicine and Diagnostic Sciences, College of Veterinary \\ Medicine, Cornell University, Ithaca, NY, USA \\ Email: $\underline{\text { hom1@cornell.edu }}$
}

Received 23 February 2015; accepted 9 April 2015; published 10 April 2015

Copyright (C) 2015 by authors and Scientific Research Publishing Inc.

This work is licensed under the Creative Commons Attribution International License (CC BY). http://creativecommons.org/licenses/by/4.0/

\section{Open Access}

\section{Abstract}

Salmonella spp. is one of the most important food- and waterborne pathogens implicated in human and animal disease. A repeat cross-sectional study was performed to assess the occurrence of Salmonella in dairy herds in a watershed and determine the factors that play a role in the likelihood of perpetuation of this organism among animals on these farms. A convenience sample of herds in the Delaware County watershed was selected based on farmers' willingness to participate. Fecal samples were collected per rectum from a representative sample of cattle in these herds and tested for the presence of Salmonella using a combination of culturing and molecular detection methods. The significance of association between the putative risk factors and the likelihood of Salmonella spp. was evaluated using the logistic regression analysis. A total of 34 dairy farms were enrolled in the study and 1987 samples were collected coinciding with seasonal variation. Salmonella spp. was detected in $44 \%(15 / 34)$ of the herds in the study population (i.e., from at least one animal in these herds). However, only a small fraction of the entire sampling population (1.7\%) was found to be shedding Salmonella. Risk factors that were found to be associated with the presence of the pathogen on the farm in the final multivariable model included concrete flooring for calves, prevention of calf access to the dam, and the lack of a designated calving pen. Two serovars, Salmonella enterica serovar Infantis and Salmonella enterica serovar Oranienburg, were identified among the isolates recovered in this study. Our study demonstrated that there was a potential risk of watershed degradation from Salmonella associated with cattle.

\section{Keywords}

Salmonella, Risk, Dairy Cows, Watershed, Polymerase Chain Reaction (PCR)

\footnotetext{
${ }^{*}$ Corresponding author.
} 


\section{Introduction}

Salmonella is a pathogen that can have serious effects on human health. The CDC recognizes 42,000 cases of salmonellosis in the United States each year, but because many cases go unreported, the actual number of cases may be up to thirty times greater [1]. The CDC attributes approximately 600 deaths to acute salmonellosis each year. Furthermore, Salmonella has a somewhat low infective dose, and it has been shown that as few as $10^{3}$ Salmonella cells are enough to produce infection in humans, though this number varies depending on the infecting strain and other host risk factors [2] [3]. It has been shown that in some cases, once an individual is enterically infected with Salmonella, it is possible for the pathogen to spread systemically via the blood and lymph vessels, leading to some chronic conditions, including reactive arthritis, osteomyelitis, cardiac inflammation, and neural disorders [4]. In addition to its impact on health, Salmonella and its associated illnesses have become an economic burden to society. The average annual cost of medical care and loss of productivity due to Salmonella infection in the United States ranges from \$0.5 to \$4.4 billion [5] [6].

Cows are a known reservoir for Salmonella, showing large variability in both shedding levels and serovars present. A variety of Salmonella serovars have been isolated from diarrheic and healthy lactating cows [7]-[10]. The presence of this pathogen on farms makes Salmonella a known risk for water and environmental degradation, and makes understanding the interaction between agent, host, and environmental factors a priority for watershed protection.

The factors influencing spread of Salmonella are of great importance because of the zoonotic potential of this pathogen, particularly in our sampling area, a heavily populated watershed. The development of cost-effective strategies to control the risk associated with this pathogen depends largely on identifying the factors that contribute to its introduction, transmission, and perpetuation in dairy herds.

Cattle were targeted in this study due to the large number of dairy herds in the Delaware County Watershed compared with other potential carriers of Salmonella. Watersheds typically serve two major groups of users, i.e., those who utilize its water resources for potable purposes, and those who live, work, or play within its boundaries. Risk assessment of watersheds is important due to the large number of people that may be affected by its potential hazards. It is vital that watershed ecohealth is managed in a way beneficial to all users by sustaining the natural basis of the watershed while sustaining it as a viable food producing and economic entity. The objectives of this study were to assess the occurrence of Salmonella in dairy herds in a watershed and determine the factors that play a role in the likelihood of perpetuation of this organism among animals on these farms.

\section{Materials and Methods}

We carried out a repeated cross-sectional epidemiologic study to address the stated objectives. This epidemiologic design involves sampling the target population several times and these times coincide with the season of the year and the design was intended to capture the potential variability in the likelihood of the occurrence of Salmonella spp.

\subsection{Target and Study Populations}

The target population consisted of all cattle on dairy farms within the approximately 275 square mile portion of the Delaware County Watershed in New York. This region spans the northern border of the county and covers approximately $20 \%$ of the county's 1460 square miles. A repeat cross-sectional study was designed and conducted over a period of one year. Each herd was sampled 3 times over this period of time to account for any potential seasonal variation in the shedding of Salmonella spp.

The study population consisted of 34 dairy farms selected from the target population of approximately 100 farms. A block sampling design was adopted to ensure representation of all geographic areas covered by the target population. In this design, the watershed was divided into sub-basins and farms were randomly selected from within each of these sub-basins. Within this framework, a proportional sampling scheme was also utilized. Thus, while all areas were represented among the selected farms, more study farms were included from those areas with a relatively higher proportion of dairy operations. While following the above study design, a participatory approach was employed for the selection of study farms. This approach involved collaboration with the Delaware County Soil and Water Conservation District (DCSWCD) and representatives of the local farmers' association. The collaborators provided planning and logistical support and facilitated study farm selection by 
granting access to their on-going, countywide farm census data. In addition to providing census data, the collaborators also provided detailed local knowledge during the study farm selection phase. We believe that the participatory approach, in conjunction with a proportional block design, led to the selection of a representative study population.

\subsection{Risk Factor Data Collection}

Information about individual cows that were sampled as well as herd level data were collected on each farm in the form of a written questionnaire or personal interview conducted with the farm owner. Data that were collected on individual animals included age, breed, reproductive status, and fecal score. Herd level data were collected for the following categories: calf housing, colostrum administration, presence of other species on the farm, manure management, and herd management. A list of risk factors for which data were collected as well as a description of the variable is characterized in Table 1.

\subsection{Sample Collection}

An age-stratified sampling design was employed to collect fecal samples on the study farms. Animals less than one year of age were perceived to be at a high risk of shedding the pathogen and were differentially targeted. The fecal sampling protocol called for the sampling of all calves on study farms less than 1 year of age, up to a maximum of 11 animals. Fecal samples were also collected from 9 animals that were older than one year of age. Animals were selected for sampling using a systematic approach.

The samples were collected seasonally, farms were visited each season-spring, winter, and summer/fall. The seasons were defined by the following cut-off dates: June 18 to October 9 denoting summer/fall, October 10 to March 12 denoting winter, and March 13 to June 17 denoting spring. At each collection, 20 samples (13 - 50 g) of feces each were collected directly from the rectum. These were placed in plastic collection vials and transported in ice boxes to the lab for processing immediately the following morning.

\subsection{Salmonella Detection}

Polymerase chain reaction (PCR) detection of Salmonella in these samples was performed using the BAX Automated System (DuPont Qualicon, DuPont Nutrition \& Health, Molecular Diagnostics, Wilmington, DE), which has been validated for use in bovine fecal samples [11]. The protocol used for amplification prior to detection of Salmonella in these samples was a modified version of a protocol developed by DuPont Qualicon for use with the BAX system. Sterile flasks of $125 \mathrm{~mL}$ buffered peptone water and $2.5 \mathrm{mg}$ novobiocin (BD Diagnostic Systems, Franklin Lake, NJ) were inoculated with $12.5 \mathrm{~g}$ of fecal sample. These flasks were incubated at $37^{\circ} \mathrm{C}$ for 20 - 24 hours. At the end of the incubation, $20 \mu \mathrm{L}$ of this primary enrichment was used to inoculate a secondary enrichment consisting of $1 \mathrm{ml}$ of brain heart infusion media (BHI-BD Diagnostic Systems, Franklin Lake, NJ) in sterile $2 \mathrm{~mL}$ tubes. These were incubated for another 24 hours at $37^{\circ} \mathrm{C}$. Additionally, our Salmonella isolates were sent to the National Veterinary Services Laboratory (NVSL) for serotyping.

\subsection{Statistical Analysis}

A systematic approach was used to evaluate the data. The bivariable association between each of the putative risk factors at the individual animal level was evaluated using the univariate logistic regression in SPSS (IBM Corporation, Armonk, NY). The outcome of interest was Salmonella spp. infection status (1= yes; $0=$ no). Accurate data on ages for some adult cows were not available, so for purposes of data analysis the age of these adults was assumed to be 730 days (2 years). Herd level data were analyzed in blocks by category, as indicated above. Factors that were significant in the bivariable association and that appeared biologically plausible were further considered in the multivariable analysis to assess their significance while simultaneously controlling for the effect of other factors using backward selection procedure. The variables used in these analyses are listed in Table 1, along with information about the coding of these variables. For all dichotomous variables, the factor coded as " 1 ” was used at the reference group. For all categorical variables, the reference group is the first listed in the table.

In addition, because the sampling units, animals, were clustered by farms, it was assumed that this grouping would lead to a correlation in the likelihood of positive results for Salmonella. Ignoring the intracluster correla- 
Table 1. List of farm management variables that were used in the analysis followed by description of the variable.

\begin{tabular}{|c|c|c|}
\hline Category & Variable name & Description of the variable \\
\hline \multirow{8}{*}{ Calf management } & Calf housing & Calves housed indoors or outdoors, coded: outdoors $=0$, indoors $=1$ \\
\hline & Calf with mother & Whether or not the calf has access to the dam or not, coded: no $=0$, yes $=1$ \\
\hline & Calf in cow barn & Whether or not that calf is housed in the same barn as the cows, coded: no $=0$, yes $=1$ \\
\hline & Calf floor & Calf flooring material, coded: dirt $=0$, concrete $=1$ \\
\hline & Greenhouse & Calves housed in greenhouse, coded: no $=0$, yes $=1$ \\
\hline & Calf tied in barn & Whether calves are tied in the barn, coded: no $=0$, yes $=1$ \\
\hline & Individual calf housing & Calves in individual housing, coded: no $=0$, yes $=1$ \\
\hline & Calf group pen & Calves in group pens, coded: no $=0$, yes $=1$ \\
\hline \multirow{5}{*}{$\begin{array}{l}\text { Colostrum } \\
\text { administration }\end{array}$} & Nursing & Calves allowed to nurse from dam, coded: no $=0$, yes $=1$ \\
\hline & Bottle & Calves bottle fed, coded: no $=0$, yes $=1$ \\
\hline & Amount colostrum & Amount of colostrum fed in quarts \\
\hline & Colostrum per day & How many times colostrum is fed per day \\
\hline & Colostrum days & How many days colostrum is administered \\
\hline \multirow{3}{*}{$\begin{array}{l}\text { Post weaning } \\
\text { management }\end{array}$} & Post weaning housing & $\begin{array}{l}\text { Type of housing for post weaned heifers, coded: } \\
\text { greenhouse }=0 \text {, cowbarn }=1 \text {, outdoor pen }=2 \text {, heifer barn }=3\end{array}$ \\
\hline & Post weaning stall & Freestall vs. tiestall, coded: freestall $=0$, tiestall $=1$ \\
\hline & Post weaning floor & Hay vs. dust flooring, coded: dust $=0$, hay $=1$ \\
\hline \multirow{6}{*}{ Herd management } & Closed herd & Whether herd is closed or not, coded: no $=0$, yes $=1$ \\
\hline & Calving area & Presence of designated calving area, coded: $n o=0$, yes $=1$ \\
\hline & Bedding frequency & $\begin{array}{l}\text { Frequency of calving area bedding, coded: } \\
\text { monthly }=0 \text {, once daily }=1 \text {, twice daily }=2 \text {, weekly }=3 \text {, }\end{array}$ \\
\hline & Medicated feed & Feed medication, coded: none $=0$, antibiotics $=1$, anticoccidial $=2$ \\
\hline & Water source & Herd water source, coded: well $=0$, spring $=1$ \\
\hline & Water treatment & Water treatment method, coded: no treatment $=0, \mathrm{UV}=1$, chemical $=2$ \\
\hline \multirow{2}{*}{$\begin{array}{c}\text { Manure } \\
\text { management }\end{array}$} & Frequency & $\begin{array}{l}\text { Frequency of manure spreading, coded: } \\
0=\text { daily, } 1=\text { weekly, } 2=\text { monthly, } 3=\text { yearly or less }\end{array}$ \\
\hline & Spread with & Mechanism of manure spreading, coded: $0=$ tractor, $1=$ vee spreader, $2=$ truck \\
\hline \multirow{8}{*}{ Other species } & Dogs & Presence, coded: no $=0$, yes $=1$ \\
\hline & Cats & Presence, coded: no $=0$, yes $=1$ \\
\hline & Rabbits & Presence, coded: no $=0$, yes $=1$ \\
\hline & Horses & Presence, coded: no $=0$, yes $=1$ \\
\hline & Goat & Presence, coded: no $=0$, yes $=1$ \\
\hline & Sheep & Presence, coded: no $=0$, yes $=1$ \\
\hline & Chickens & Presence, coded: no $=0$, yes $=1$ \\
\hline & Pigs & Presence, coded: no $=0$, yes $=1$ \\
\hline
\end{tabular}

tion among animals within herds in the analysis could lead to incorrect estimates of the effects and hence incorrect interpretation of associations between the occurrence of the organism and the type of sample. A correlation in the likelihood of Salmonella might arise due to observed or unobserved risk factors. In order to test if there was a cluster effect associated with the likelihood of Salmonella, it was assumed that the unobserved risk factors were randomly distributed among farms and the overall significance of this assumption was evaluated by using a mixed-effect logistic regression model [12]. The likelihood ratio test was used to evaluate the significance of the farms' random effect parameter in the mixed model. The mixed effect logistic regression analysis was per- 
formed using the EGRET statistical software (Cytel Statistical Software, MA). The effect of each factor on the likelihood of infection with the organism was quantified by the odds ratio (OR), which was computed as the exponent of the respective regression coefficient in the logistic regression model.

\section{Results}

A total of 1987 samples were collected from 34 herds enrolled in the study, with each herd sampled three times during the course of the study. Descriptive statistics for the study population are presented in Table 2 and Table 3. Each herd was sampled once during the summer/fall, winter, and spring. Thirty-three samples were positive for Salmonella leading to an overall shedding prevalence of $1.7 \%$ (95\% confidence interval: 1.10, 2.22). At the herd level, $44 \%$ of the herds sampled had at least one animal detected to be shedding Salmonella spp. over the course of the study. Of the farms that were detected to have at least one animal shedding Salmonella, within herd prevalence ranged between $1.3 \%$ - 5\%, except one farm that had a within herd prevalence of $20.6 \%$. No significant clustering of shedding of Salmonella by farm was observed when the data were analyzed using a hierarchical data analysis approach.

Table 2. Descriptive statistics of the host related factors that were investigated the study population.

\begin{tabular}{|c|c|c|c|}
\hline \multicolumn{2}{|c|}{ Factor } & \multirow{2}{*}{$\begin{array}{c}\text { Frequency } \\
1853\end{array}$} & \multirow{2}{*}{$\begin{array}{c}\text { Percentage } \\
0.93\end{array}$} \\
\hline \multirow{5}{*}{ Breed } & Holstein & & \\
\hline & Jersey & 98 & 0.05 \\
\hline & Swiss & 14 & 0.008 \\
\hline & Guernsey & 3 & 0.002 \\
\hline & Cross & 21 & 0.01 \\
\hline \multirow{2}{*}{ Gender } & Female & 1924 & 0.97 \\
\hline & Male & 65 & 0.03 \\
\hline \multirow{2}{*}{ Age } & $<6$ months & 812 & 0.41 \\
\hline & $>6$ months & 1177 & 0.59 \\
\hline \multirow{4}{*}{ Fecal score } & Loose & 1833 & 0.92 \\
\hline & Runny & 82 & 0.04 \\
\hline & Mucoid & 11 & 0.01 \\
\hline & Dry & 62 & 0.03 \\
\hline
\end{tabular}

Table 3. Management factors that were significantly associated with the likelihood of Salmonella spp. among the study population as identified at screening using the univariate logistic regression analysis.

\begin{tabular}{|c|c|c|c|c|c|}
\hline \multirow{2}{*}{ Factor } & \multirow{2}{*}{ Regression coefficient } & \multirow{2}{*}{ SE } & \multirow{2}{*}{$\begin{array}{l}\text { Odds Ratio } \\
\text { (OR) }\end{array}$} & \multicolumn{2}{|c|}{ 95\% C.I. } \\
\hline & & & & Lower & Upper \\
\hline Calf housing & -0.989 & 0.472 & 0.4 & 0.1 & 0.9 \\
\hline Calf with mother & 1.372 & 0.489 & 3.9 & 1.5 & 10.3 \\
\hline Calf in cow barn & -1.372 & 0.568 & 0.3 & 0.1 & 0.8 \\
\hline Calf flooring & -3.454 & 0.207 & 0.2 & 0.1 & 0.5 \\
\hline Cats & -2.206 & 0.368 & 0.1 & 0.1 & 0.3 \\
\hline Goat & -2.175 & 1.039 & 0.1 & 0.02 & 0.9 \\
\hline Pigs & 2.616 & 0.366 & 13.7 & 6.7 & 28 \\
\hline Closed herd & -1.650 & 0.557 & 0.2 & 0.1 & 0.6 \\
\hline Water source & -0.919 & 0.486 & 0.4 & 0.2 & 1 \\
\hline Calving area & 1.715 & 0.461 & 5.6 & 2.3 & 13.7 \\
\hline
\end{tabular}


In analysis by season, winter had a prevalence of $2 \%$, followed by summer/fall at $1.7 \%$, and then spring at $1.3 \%$ (Figure 1). There was no significant difference found between the seasons. Adult cows had a prevalence of $1.6 \%$, and calves and heifers under one year of age had a prevalence of $1.7 \%$. There was also no significant difference in prevalence between the two age groups. All Salmonella positive samples were from Holstein cows, with the exception of one positive Jersey cow. The risk factors that were found to be significant in the univariate and multivariable analysis are listed in Table 3 and Table 4 respectively. The final model indicated that concrete flooring for calves, preventing calf access to the dam, and lack of a designated calving area are all associated with an increased risk of Salmonella infection.

Three of the isolates were able to be serotyped by the NVSL, two of which were identified as Salmonella enterica servovar Infantis and one was identified as Salmonella enterica serovar Oranienburg.

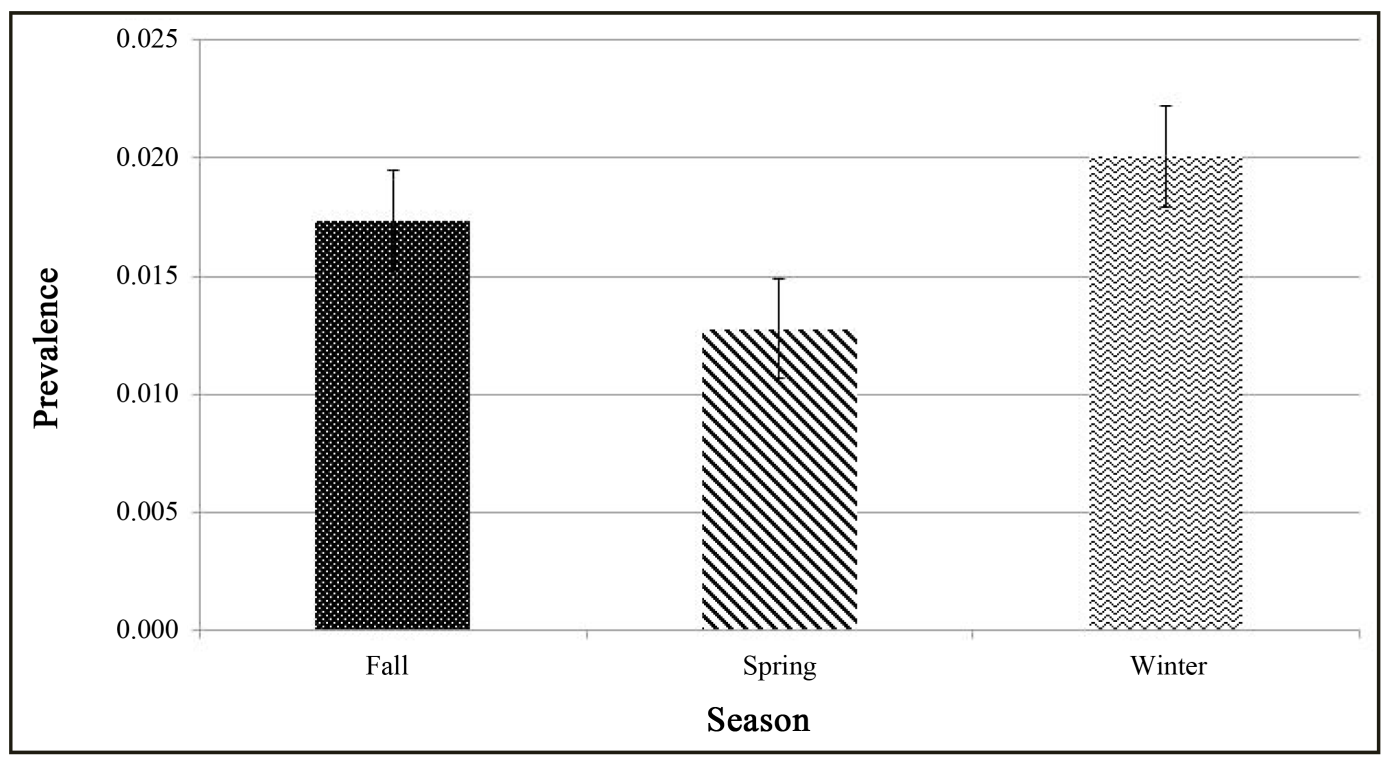

Figure 1. The prevalence of Salmonella spp. among the sampled population by season of the year.

Table 4. Factors that were significantly associated with the likelihood of Salmonella spp. among cattle in the watershed after controlling for the presence of other factors multiple logistic regression analysis.

\begin{tabular}{|c|c|c|c|c|c|}
\hline \multirow{2}{*}{ Factor } & \multirow{2}{*}{ Regression coefficient } & \multirow{2}{*}{ SE } & \multirow{2}{*}{$\begin{array}{l}\text { Odds Ratio } \\
\quad \text { (OR) }\end{array}$} & \multicolumn{2}{|c|}{ 95\% C.I. } \\
\hline & & & & Lower & Upper \\
\hline Constant & -6.031 & 0.609 & --- & --- & --- \\
\hline Calf with mother & 2.607 & 0.500 & 27.2 & 5.1 & 36 \\
\hline Calf flooring & -1.986 & 0.461 & 0.1 & 0.1 & 0.3 \\
\hline Calving area & 1.951 & 0.460 & 7 & 2.9 & 17.3 \\
\hline
\end{tabular}

\section{Discussion}

The total prevalence of Salmonella spp. among these dairy cows was found to be $1.7 \%$, which is lower than estimates from previous studies. Salmonella prevalence reported among other cattle populations in the US ranged from $0 \%-10.1 \%$ [9] [13]-[15]. However, the herd prevalence reported in this study is comparable to the findings in other studies involving dairy herds, with herd prevalence estimates ranging from $31 \%$ to $77 \%$ [9] [10] [16] [17]. The differences in the prevalence among these different studies could be attributed to the difference in the management among these populations and the diagnostic methods used in the detection of the pathogen.

Though Salmonella was found in only 33 cows of nearly 2000 that were sampled for this study, the possibility exists that other cows were harboring this bacteria but not shedding it in their feces. It has been shown that following infection with Salmonella, particularly S. dublin, some cows become carriers of the disease without 
shedding [18]. These carrier cows will not normally shed the organism in the feces, but can intermittently shed the organism if put under stress. Great variation in frequency of shedding has been shown previously on several dairy farms at different sampling times. The prevalence of Salmonella on four large dairy operations in the southwestern US ranged between 0\% - 93\% in one study [19].

In our approach to identify factors that were significantly associated with the likelihood of shedding Salmonella spp. we controlled for the potential overdispersion or increased variability due to the unobserved factors using the random effect models [12]. There are several models that are available to in the literature to account for the potential overdispersion and the choice depend on which model fits the collected data. We opted to use the logistic-binomial model because it did fit the data best and we found that there was no significant overdispersion. There are several explanations for this finding including the low prevalence of shedding of Salmonella spp. and the lack of variability among herds. The need for using these special models in the analysis of the data is to control for the potential overdispersion that results from the fact that cows within a herd might have similar risk of shedding of Salmonella in comparison to cows among herds in the watershed. We found no significant overdispersion and that could be attributed to the fact that cattle in this population is managed in similar way [17].

Another consideration for the low prevalence that we found would be the method in which the samples were tested. Some might argue that the BAX Automated System was originally designed to test for bacterial pathogens in food products; however it has shown great potential in evaluating the prevalence of bacteria in a population by testing fecal samples [11]. Fecal samples tend to be less clean than food products, and therefore it is more difficult to grow and detect Salmonella in these samples because of other species of competitive bacteria and other organisms. Due to the dirty nature of our samples, it is possible that our study may have underestimated the actual prevalence of Salmonella among these dairy farms.

It was slightly surprising to find that there was no significant difference in Salmonella prevalence between the seasons. Most researchers find a greater prevalence during the warmer seasons than during the winter. A study conducted among organic and conventional farms in Minnesota, Wisconsin, Michigan, and New York found a prevalence of only $2.7 \%$ in the winter as compared to $4.9 \%, 6.4 \%$, and $5.1 \%$ prevalence in spring, summer and fall respectively [17]. It has been speculated that the organism is more common during the warmer seasons because it can survive longer outside of the host in order to perpetuate the cycle of re-infection within a herd. However, it is possible that warm, wet areas inside the barn, such as water troughs or residual manure on barn cleaning equipment, could provide a place for bacteria to survive and multiply during cold months.

It is not surprising that lack of a designated calving area is associated with 7 times greater odds of Salmonella detection in a herd. Many of these farms that do not have a separate calving pen will often allow their pregnant cows to calve in the sick pen. This exposes peri-parturient cows that are immunosuppressed as well as newly born calves that are immunologically naïve to sick animals that may be shedding pathogens, including Salmonella. The authors hypothesize that the increased odds of Salmonella associated with concrete flooring $(\mathrm{OR}=10)$ are due to the tendency of concrete to develop small crevices and holes over time that make it difficult to clean and allow Salmonella organisms to survive in small pockets of organic material within the small pores.

The association between preventing calf access to the dam and increased odds of Salmonella $(\mathrm{OR}=27)$ is not as clear cut. It has been postulated that adult cows may serve as a source of infection for their calves, who are immunologically naïve. Under this notion, it is common practice on most farms for calves to be removed from the dam as soon as possible and placed in some type of individual housing. However, it is possible that continued calf exposure to small amounts of Salmonella at a young age may induce an immunological response that prevents colonization by the pathogen. Similarly, calf exposure to the dam's normal gut flora may result in colonization of the calf's gut with this normal flora and prevention of Salmonella infection through competition. More research is needed to identify the mechanism behind this association.

The identification of the two serovars, S. infantis and S. oranienburg, in the watershed is noteworthy, especially since these were the only strains that were identified. Both of these serovars can cause infection in humans, as well as in other species such as poultry and swine. In 2005, S. oranienburg and S. infantis ranked in at eleven and thirteen respectively on the CDC's list of the most frequently reported Salmonella serovars from human sources. The presence of these pathogenic Salmonella strains indicates the need to minimize the spread of Salmonella on these dairy farms and potentially into the water system through farm management practices. This also shows the need for further studies that will provide more information about the strains of Salmonella that are present on these farms, and how Salmonella is perpetuated within the watershed. 


\section{Conclusion}

In conclusion, our study demonstrated that cattle in this watershed are infected Salmonella spp. and shed this waterborne pathogen in the environment. Some of the species that were shed are known to have zoonotic potential, contribute to the degradation of the environment and pose risk to the watershed user. Risk mitigation intervention strategies should be recommended for the farmers and the users to control and minimize the associated likelihood of adverse consequences.

\section{Acknowledgements}

The authors would like to thank the Delaware County Soil and Water Conservation District (DCSWCD), Delaware County Department of Watershed Affairs and associated dairy farmers for their continued support of our research. This research was supported by funding from the USDA-CREFF.

\section{References}

[1] Food Net (2010) Trends in Foodborne Illness, 1996-2010. www.cdc.gov/foodsafety

[2] Bronze, M.S. and Greenfield, R.A. (2005) Biodefense Principles and Pathogens. Horizon Bioscience. Norfolk.

[3] Ryan, K.J., Ray, C.G., Ahmad, N., Drew, W.L. and Plorde, J. (2010) Sherris Medical Microbiology: An Introduction to Infectious Disease. 5th Edition, McGraw-Hill, New York.

[4] D’Aoust, J.-Y. (1994) Salmonella and the International Food Trade. International Journal of Food Microbiology, 24, 11-31. http://dx.doi.org/10.1016/0168-1605(94)90103-1

[5] Kennedy, M., Villar, R., Vugia, D.J., Rabatsky-ehr, T., Farley, M.M., Pass, M., Smith, K., Smith, P., Cieslak, P.R., Imhoff, B. and Griffin, P.M. (2004) Hospitalizations and Deaths Due to Salmonella Infections, Foodnet, 1996-1999. Clinical Infectious Diseases, 38, 1996-1999. http://dx.doi.org/10.1086/381580

[6] Scharff, R.L. (2012) Economic Burden from Health Losses Due to Foodborne Illness in the United States. Journal of Food Protection, 75, 123-131. http://dx.doi.org/10.4315/0362-028X.JFP-11-058

[7] Fitzgerald, A.C., Edrington, T.S., Looper, M.L., Callaway, T.R., Genovese, K.J., Bischoff, K.M., McReynolds, J.L., Thomas, J.D., Anderson, R.C. and Nisbet, D.J. (2003) Antimicrobial Susceptibility and Factors Affecting the Shedding of E. coli O157:H7 and Salmonella in Dairy Cattle. Letters in Applied Microbiology, 37, 392-398. http://dx.doi.org/10.1046/j.1472-765X.2003.01417.x

[8] Blau, D.M., McCluskey, B.J., Ladely, S.R., Dargatz, D.A., Fedorka-Cray, P.J., Ferris, K.E. and Headrick, M. (2005) Salmonella in Dairy Operations in the United States: Prevalence and Antimicrobial Drug Susceptibility. Journal of Food Protection, 68, 696-702.

[9] Cummings, K.J., Warnick, L.D., Elton, M., Gröhn, Y.T., McDonough, P.L. and Siler, J.D. (2010) The Effect of Clinical Outbreaks of Salmonellosis on the Prevalence of Fecal Salmonella Shedding among Dairy Cattle in New York. Foodborne Pathogens and Disease, 7, 815-823. http://dx.doi.org/10.1089/fpd.2009.0481

[10] USDA APHIS (2011) NAHMS: Salmonella, Listeria, and Campylobacter on US Dairy Operations, 1996-2007. http://www.aphis.usda.gov/animal_health/nahms/dairy/

[11] Bordonaro, R., McDonough, P.L., Chang, Y.F. and Mohammed, H.O. (2013) Molecular Detection of Salmonella Species in Bovine Fecal Samples. Journal of Veterinary Diagnostic Investigation, 25, 756-758. http://dx.doi.org/10.1177/1040638713508123

[12] Rosner, B., Willett, W.C. and Spiegelman, D. (1989) Correction of Logistic Regression Relative Risk Estimates and Confidence Intervals for Systematic Within-Person Measurement Error. Statistics in Medicine, 8, 1051-1069. http://dx.doi.org/10.1002/sim.4780080905

[13] Hyatt, D.R., Galland, J.C., Crupper, S., Hawkins, L., Anderson, N.V. and Stokka, G.L. (1998) Prevalence, Antibiotic Susceptibility, and Genetic Diversity of Salmonella, Campylobacter, and Escherichia coli O157:H7 Collected at Four Kansas Beef Cattle Feedyards over 13 Months. In: Cattleman's Day, Kansas State University, Agricultural Experiment Station and Cooperative Extension Service, Manhattan, 96-97.

[14] Wells, S.J., Fedorka-Cray, P.J., Dargatz, D.A., Ferris, K. and Green, A. (2001) Fecal Shedding of Salmonella spp. by Dairy Cows on Farm and at Cull Cow Markets. Journal of Food Protection, 64, 3-11.

[15] Warnick, L.D., Kaneene, J.B., Ruegg, P.L., Wells, S.J., Fossler, C., Halbert, L. and Campbell, A. (2003) Evaluation of Herd Sampling for Salmonella Isolation on Midwest and Northeast US Dairy Farms. Preventive Veterinary Medicine, 60, 195-206. http://dx.doi.org/10.1016/S0167-5877(03)00141-7

[16] Huston, C.L., Wittum, T.E. and Love, B.C. (2002) Persistent Fecal Salmonella Shedding in Five Dairy Herds. Journal 
of the American Veterinary Medical Association, 220, 650-655. http://dx.doi.org/10.2460/javma.2002.220.650

[17] Fossler, C.P., Wells, S.J., Kaneene, J.B., Ruegg, P.L., Warnick, L.D., Bender, J.B., Eberly, L.E., Godden, S.M. and Halbert, L.W. (2005) Herd-Level Factors Associated with Isolation of Salmonella in a Multi-State Study of Conventional and Organic Dairy Farms II. Salmonella Shedding in Calves. Preventive Veterinary Medicine, 70, $279-291$. http://dx.doi.org/10.1016/j.prevetmed.2005.04.002

[18] Watson, W., Wood, B. and Richardson, A. (1971) Salmonella Dublin Infection in a Beef Herd. British Veterinary Journal, 127, 294-298.

[19] Edrington, T.S., Hume, M.E., Looper, M.L., Schultz, C.L., Fitzgerald, A.C., Callaway, T.R., Genovese, K.J., Bischoff, K.M., McReynolds, J.L., Anderson, R.C. and Nisbet, D.J. (2004) Variation in the Faecal Shedding of Salmonella and E. coli O157:H7 in Lactating Dairy Cattle and Examination of Salmonella Genotypes Using Pulsed-Field Gel Electrophoresis. Letters in Applied Microbiology, 38, 366-372. http://dx.doi.org/10.1111/j.1472-765X.2004.01495.x 